\title{
Investigating the relationships between the burden of multiple sensory hypersensitivity symptoms and headache-related disability in patents with migraine
}

Keisuke Suzuki ${ }^{1 *}$, Shiho Suzuki ${ }^{1}$, Tomohiko Shiina ${ }^{1}$, Madoka Okamura', Yasuo Haruyama², Muneto Tatsumoto ${ }^{3}$ and Koichi Hirata ${ }^{1}$

\begin{abstract}
Objective: Sensory hypersensitivities such as photophobia, phonophobia, and osmophobia are common in patients with migraine. We investigated the burden of these multiple sensory hypersensitivities in migraine.

Methods: In this cross-sectional study, 187 consecutive patients with migraine (26 men/161 women; age, $45.9 \pm$ 13.2 years) were included. Sensory hypersensitivity symptoms such as photo-/phono-/osmophobia and accompanying symptoms were determined by neurologists in interviews. The Migraine Disability Assessment (MIDA S) was used to assess headache-related disability. The Kessler Psychological Distress Scale (K6) was also administered.

Results: Photophobia, phonophobia and osmophobia were observed in $75.4 \%, 76.5 \%$ and $55.1 \%$ of the patients with migraine, respectively. A significant overlap in sensory hypersensitivities (photo-/phono-/osmophobia) was found; the proportions of patients with 2 and 3 coexisting sensory hypersensitivities were $33.2 \%$ and $41.7 \%$, respectively. The MIDAS score was higher in those with 3 sensory hypersensitivity symptoms than in those with 0 to 2 sensory hypersensitivity symptoms. A generalized linear model with ordinal logistic regression analysis revealed that multiple sensory hypersensitivities, younger age, more migraine days per month, and a higher K6 score were significantly related to the higher MIDAS score.
\end{abstract}

Conclusion: Our study showed that sensory hypersensitivities commonly occur and overlap in patients with migraine and that multiple sensory hypersensitivity symptoms have a significant impact on headache-related disability.

Keywords: Migraine, Sensory hypersensitivity symptoms, Headache-related disability

\footnotetext{
*Correspondence: keisuke@dokkyomed.ac.jp

'Department of Neurology, Dokkyo Medical University, 880 Kitakobayashi, Mibu, Shimotsuga, Tochigi 321-0293, Japan
}

Full list of author information is available at the end of the article

\section{$\triangle B M C$}

(c) The Author(s). 2021 Open Access This article is licensed under a Creative Commons Attribution 4.0 International License, which permits use, sharing, adaptation, distribution and reproduction in any medium or format, as long as you give appropriate credit to the original author(s) and the source, provide a link to the Creative Commons licence, and indicate if changes were made. The images or other third party material in this article are included in the article's Creative Commons licence, unless indicated otherwise in a credit line to the material. If material is not included in the article's Creative Commons licence and your intended use is not permitted by statutory regulation or exceeds the permitted use, you will need to obtain permission directly from the copyright holder. To view a copy of this licence, visit http://creativecommons.org/licenses/by/4.0/ The Creative Commons Public Domain Dedication waiver (http://creativecommons.org/publicdomain/zero/1.0/) applies to the data made available in this article, unless otherwise stated in a credit line to the data. 


\section{Introduction}

Migraine is a chronic neurologic disorder affecting over 1 billion people worldwide and is known to be the leading cause of disability worldwide in people younger than 50 years [1]. Migraine is characterized by moderate to severe headache, nausea/vomiting and hypersensitivity to visual, auditory and olfactory stimuli. Photophobia, phonophobia and osmophobia are common triggers of migraine attacks and are observed in 50-90\%, 52-82\% and $25-43 \%$ of patients with migraine, respectively [2]. These sensory hypersensitivities are implicated in the underlying pathophysiology of migraine and are related to one another. In previous studies, photophobia was a predictor of osmophobia in patients with migraine [3], and migraine patients with cutaneous allodynia had lower sound aversion thresholds [4]. These observations suggest that migraine is related to not only unimodal sensory processing but also multimodal sensory integration [2]. Headache intensity has been significantly correlated with nausea, vomiting, photophobia, phonophobia, and osmophobia in patients with migraine [5]. However, the impact of these multiple sensory hypersensitivity symptoms on headache-related severity has not been well studied. We conducted a cross-sectional study by hypothesizing that the greater the number of sensory sensitivities a patient has, the greater the effect on the degree of headache-related disability.

\section{Methods}

In a single-center, cross-sectional setting, 200 consecutive outpatients with migraine ( 30 men/170 women; age, $46.2 \pm 13.4$ years) were initially recruited; those with incomplete data $(n=13)$ were excluded, for a final sample size of 187. The diagnosis of migraine was made by headache specialists according to the International Classification of Headache Disorders, 3rd edition [6]. Patients with organic brain disease other than migraine were excluded by brain magnetic resonance imaging. This study was approved by the institutional review boards of the Dokkyo Medical University Hospital. All participants provided written informed consent to participate in the study.

Duration of illness, habits (smoking, alcohol consumption, and caffeine consumption), the use of acute and chronic medications for migraine, and aura status were obtained based on clinical medical records. The patients were asked about accompanying symptoms and the presence of photo-/phono-/osmophobia and allodynia during both ictal and interictal phases in face-to-face interviews with headache specialists. The overlap of sensory hypersensitivity symptoms was also determined through face-to-face interviews. The Migraine Disability Assessment (MIDAS) [7] was used to assess disability related to headache. Psychological distress during the past
30 days was evaluated by the Kessler Psychological Distress Scale (K6) [8].

\section{Statistical analysis}

Patients with migraine were classified into four groups according to the number of sensory hypersensitivity symptoms (photophobia, phonophobia, and osmophobia) they presented. Normality was assessed by the Shapiro-Wilk test, and the MIDAS score was found to be non-normally distributed $(p<0.001)$. Therefore, the Kruskal-Wallis test followed by Bonferroni's multiple comparison test was employed to compare the MIDAS scores of the four groups. A generalized linear model

Table 1 Characteristics of patients with migraine

\begin{tabular}{|c|c|}
\hline & Patients with migraine \\
\hline $\mathrm{n}(\mathrm{M} / \mathrm{F})$ & $187(26 / 161)$ \\
\hline Age, mean $\pm S D$, years & $45.9 \pm 13.2$ \\
\hline \multicolumn{2}{|l|}{ Diagnosis, n (\%) } \\
\hline Migraine without aura & $137(73.3)$ \\
\hline Migraine with aura & $50(26.7)$ \\
\hline Chronic migraine, n (\%) & $8(4.3)$ \\
\hline Migraine days per month, mean \pm SD & $7.6 \pm 7.3$ \\
\hline Migraine onset, mean $\pm S D$, years & $18.8 \pm 8.6$ \\
\hline Disease duration, mean $\pm S D$, years & $27.1 \pm 13.5$ \\
\hline \multicolumn{2}{|l|}{ Smoking, n (\%) } \\
\hline Never & $144(77.0)$ \\
\hline Past & $29(15.5)$ \\
\hline Current & $14(7.5)$ \\
\hline \multicolumn{2}{|l|}{ Alcohol intake, n (\%) } \\
\hline Never & $99(52.9)$ \\
\hline$<1$ day/week & $60(32.1)$ \\
\hline 1-2 days/week & $16(8.6)$ \\
\hline 3-5 days/week & $5(2.7)$ \\
\hline 6-7 days/week & $7(3.7)$ \\
\hline Caffeine consumption, n (\%) & $174(93.0)$ \\
\hline Nausea & $120(64.2)$ \\
\hline Allodynia & $34(18.2)$ \\
\hline \multicolumn{2}{|l|}{ Sensory hypersensitivity, n (\%) } \\
\hline Photophobia & $141(75.4)$ \\
\hline Phonophobia & $143(76.5)$ \\
\hline Osmophobia & $103(55.1)$ \\
\hline K6 score, mean \pm SD & $5.3 \pm 5.0$ \\
\hline MIDAS score, mean \pm SD & $12.3(15.8)$ \\
\hline Acute headache medication use, n (\%) & $178(95.2)$ \\
\hline Preventive headache medication use, n (\%) & $88(47.1)$ \\
\hline Comorbidities, n (\%) & $98(52.4)$ \\
\hline Psychiatric disease, n (\%) & $13(7.0)$ \\
\hline
\end{tabular}

MIDAS Migraine Disability Assessment, K6 Kessler Psychological Distress Scale 
with ordinal logistic regression analysis was used to determine the relationship between MIDAS scores and other factors. Considering the sample size, variables with a $p$-value of less than 0.1 in the univariate analysis were entered into the multivariable analysis. Two-tailed $p$ values $<0.05$ were considered statistically significant. IBM SPSS Statistics V.26.0 (IBM SPSS, Tokyo, Japan) was used for the statistical analyses.

\section{Results}

Table 1 shows the demographic data and characteristics of the patients with migraine. The sensory hypersensitivities photophobia, phonophobia and osmophobia were observed in $75.4 \%, 76.5 \%$ and $55.1 \%$ of the patients with migraine, respectively. There was a significant overlap in sensory hypersensitivities (photo-/phono-/osmophobia); the proportions of patients with 2 and 3 coexisting sensory hypersensitivities were $33.2 \%$ and $41.7 \%$, respectively (Fig. 1). Nausea was reported by $64.2 \%$ of patients, and allodynia was observed in $18.2 \%$ of patients. In terms of the overlap of sensory hypersensitivity symptoms, the MIDAS score was higher in those with 3 sensory hypersensitivity symptoms than in those with 0 to 2 sensory hypersensitivity symptoms (Fig. 2). The number of sensory hypersensitivity symptoms was not significantly related to the presence or absence of preventive treatment (Supplementary Table 1). The generalized linear model with ordinal logistic regression analysis revealed that multiple sensory hypersensitivities, younger age, more migraine days per month and a higher K6 score were the clinical factors that contributed to a higher MIDAS score (Table 2).

\section{Discussion}

In this study, we showed a significant overlap of sensory hypersensitivity symptoms, such as photophobia, phonophobia and osmophobia, in patients with migraine. Patients with 3 coexisting sensory hypersensitivities had higher MIDAS scores than patients with fewer sensory hypersensitivities (0 to 2 ). In addition, the generalized

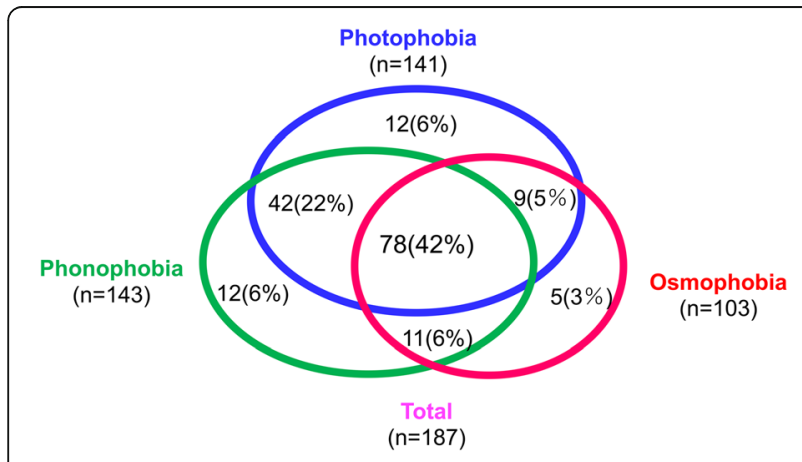

Fig. 1 Overlap of sensory hypersensitivities in patients with migraine

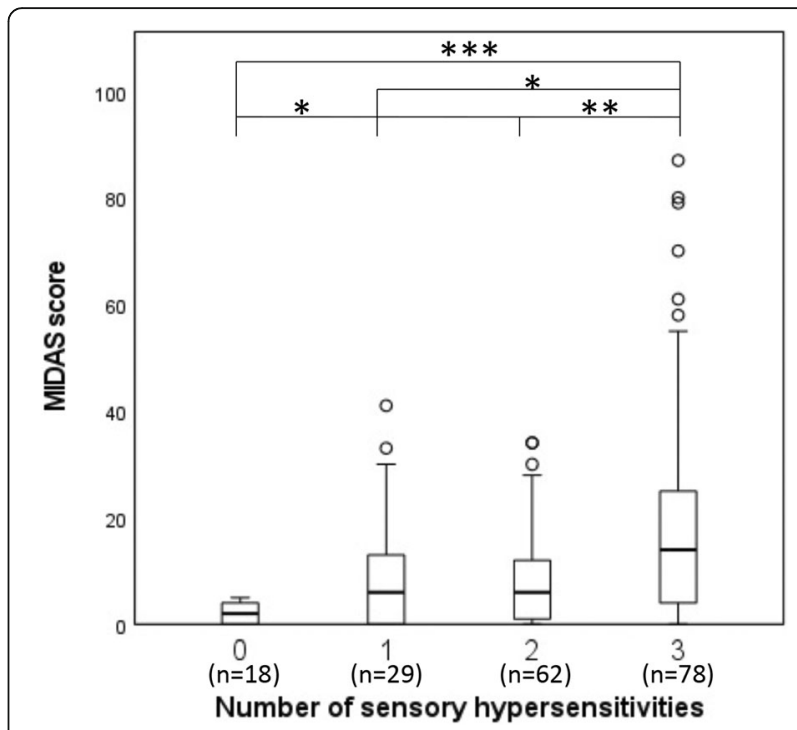

Fig. 2 Differences in MIDAS score according to number of sensory hypersensitivities. Box plots show the median, lower and upper quartile, minimum and maximum, and outliers of four sensory hypersensitivities. Each difference among the four groups was analyzed by the Kruskal-Wallis test with Bonferroni's multiple comparison test. ${ }^{*} p<0.05 ;{ }^{* *} p<0.01 ;{ }^{* *} p<0.001$.

linear model with ordinal logistic regression analysis showed that the higher the number of hypersensitivity symptoms was, the greater the degree of disability related to headache was. In a study by Kelman et al. [5], the more severe a patient's photophobia, phonophobia, osmophobia, or nausea was, the greater the intensity of the headache was; the authors suggested that the activated pain pathways might activate pathways involving accompanying symptoms such as nausea, or the pathways mediating pain and accompanying symptoms might both be activated simultaneously by another mechanism. However, the impact of the overlap of these factors was not investigated. In contrast, in 92 patients with migraine, interictal sensory hypersensitivities, calculated as combined scores for auditory and visual hypersensitivities, were related to self-perceived attention difficulties but not to headache-related disabilities [9].

Sensory hypersensitivity to stimuli is most prominent during headache attacks but may also be present during interictal periods [2]. Beyond merely accompanying headache attacks, hypersensitivities to light, sound, and smell have also been reported as premonitory symptoms or triggers before a headache attack [10]. This observation suggests that these sensory hypersensitivity symptoms may reflect abnormal brain activity at the earliest stage of a migraine attack in the absence of pain [11]. In a retrospective large-sample study, migraine patients who had nausea or photo-/osmo-/phonophobia in the premonitory phase had a significantly increased frequency of these symptoms as accompanying symptoms 
Table 2 The relationship between MIDAS scores and related factors $(n=187)$

\begin{tabular}{|c|c|c|c|c|c|c|c|c|c|c|}
\hline \multirow{3}{*}{ Male vs female } & \multicolumn{5}{|c|}{ Univariate analysis $^{\mathrm{a}}$} & \multicolumn{5}{|c|}{ Multivariable analysis $^{\mathbf{b}}$} \\
\hline & \multirow{2}{*}{$\begin{array}{l}\text { COR } \\
0.684\end{array}$} & \multicolumn{3}{|c|}{$95 \% \mathrm{Cl}$} & \multirow{2}{*}{$\begin{array}{l}\boldsymbol{p} \text { value } \\
0.312\end{array}$} & \multirow{2}{*}{$\begin{array}{l}\text { AOR } \\
0.726\end{array}$} & \multicolumn{3}{|c|}{$95 \% \mathrm{Cl}$} & \multirow{2}{*}{$\frac{p \text { value }}{0.461}$} \\
\hline & & 0.328 & - & 1.427 & & & 0.310 & - & 1.700 & \\
\hline Age, years & 0.970 & 0.952 & - & 0.989 & 0.002 & 0.977 & 0.956 & - & 0.999 & 0.038 \\
\hline Migraine without aura, yes vs no & 1.439 & 0.831 & - & 2.493 & 0.194 & & & & & \\
\hline Migraine with aura, yes vs no & 0.745 & 0.429 & - & 1.294 & 0.297 & & & & & \\
\hline Chronic migraine, yes vs no & 1.706 & 0.505 & - & 5.770 & 0.390 & & & & & \\
\hline Migraine days per month, mean \pm SD & 1.113 & 1.070 & - & 1.158 & $<0.001$ & 1.094 & 1.050 & - & 1.141 & $<0.001$ \\
\hline Nausea, yes vs no & 2.507 & 1.475 & - & 4.261 & $<0.001$ & 0.658 & 0.930 & - & 2.954 & 0.086 \\
\hline Allodynia, yes vs no & 3.057 & 1.572 & - & 5.945 & $<0.001$ & 1.977 & 0.972 & - & 4.022 & 0.060 \\
\hline Age at first migraine onset, years & 0.960 & 0.932 & - & 0.990 & 0.008 & 0.992 & 0.959 & - & 1.026 & 0.639 \\
\hline Disease duration, years & 0.986 & 0.968 & - & 1.005 & 0.149 & & & & & \\
\hline Comorbidities, yes vs no & 0.875 & 0.531 & - & 1.443 & 0.601 & & & & & \\
\hline Psychiatric disease, yes vs no & 3.593 & 1.352 & - & 9.549 & 0.010 & 1.996 & 0.675 & - & 2.867 & 0.096 \\
\hline Acute headache medication, yes vs no & 1.579 & 0.478 & - & 5.199 & 0.455 & & & & & \\
\hline Preventive headache medication, yes vs no & 1.802 & 1.084 & - & 2.994 & 0.023 & 1.622 & 0.918 & - & 2.867 & 0.096 \\
\hline \multicolumn{11}{|l|}{ Smoking } \\
\hline Never & Ref. & & & & & Ref. & & & & \\
\hline Past & 2.044 & 0.995 & - & 4.197 & 0.051 & 1.778 & 0.784 & - & 4.034 & 0.169 \\
\hline Current & 1.871 & 0.712 & - & 4.918 & 0.204 & 1.372 & 0.495 & - & 3.803 & 0.543 \\
\hline \multicolumn{11}{|l|}{ Alcohol intake, n (\%) } \\
\hline Never & Ref. & & & & & Ref. & & & & \\
\hline$<1$ day/week & 0.272 & 0.726 & - & 2.229 & 0.401 & 1.542 & 0.845 & - & 2.812 & 0.158 \\
\hline 1-2 days/week & 1.303 & 0.519 & - & 3.272 & 0.573 & 1.527 & 0.564 & - & 4.134 & 0.405 \\
\hline 3-5 days/week & 1.407 & 0.300 & - & 6.599 & 0.665 & 1.736 & 0.398 & - & 7.569 & 0.463 \\
\hline 6-7 days/week & 4.449 & 1.141 & - & 17.35 & 0.032 & 3.003 & 0.666 & - & 13.539 & 0.152 \\
\hline Caffeine intake, yes/no & 0.447 & 0.164 & - & 1.221 & 0.116 & & & & & \\
\hline \multicolumn{11}{|l|}{ Number of sensory hypersensitivities } \\
\hline 0 & Ref. & & & & & Ref. & & & & \\
\hline 1 & 3.089 & 1.085 & - & 8.794 & 0.035 & 1.921 & 0.626 & - & 5.902 & 0.254 \\
\hline 2 & 3.529 & 1.424 & - & 8.749 & 0.006 & 2.730 & 1.030 & - & 7.239 & 0.044 \\
\hline 3 & 10.427 & 4.160 & - & 26.134 & $<0.001$ & 5.974 & 4.845 & - & 13.372 & 0.002 \\
\hline K6, score & 1.123 & 1.070 & - & 1.181 & $<0.001$ & 1.068 & 1.004 & - & 1.132 & 0.038 \\
\hline
\end{tabular}

COR crude odds ratio, AOR adjusted odds ratio, 95\% CI 95\% confidence interval, MIDAS Migraine Disability Assessment, K6 Kessler Psychological Distress Scale a Using a generalized linear model with ordinal logistic regression analysis

${ }^{b}$ Using the variables that had $p$ values of less than 0.1 in the univariate analysis, except for sex

of migraine attacks, supporting the idea that hypersensitivity symptoms could be part of the migraine [12]. Neuroimaging studies also reported that non-pain symptoms of migraine were not merely part of the response to pain and produced relevant functional imaging changes even in the absence of pain [11]. Functional brain imaging studies show that patients with migraine have atypical brain activation in response to nociceptive, olfactory, and visual stimuli as well as atypical functional connectivity involved in sensory-discriminative pain processing, affective emotional processing, cognitive processing, and pain modulation [13]. Additionally, in migraine patients, exposure to odors activates the limbic and rostral pons [14], and increased activation of the visual cortex following visual stimulation has been reported [15]. Neuroimaging and electrophysiological studies have supported sensory hypersensitivity in migraine by observing that migraine patients being exposed to sensory stimuli show increased brain activation, a lack of habituation to repeated stimuli, and increased attention to incoming stimuli [16]. The role of multisensory integration in migraine has been suggested by the observation that one 
sensory modality mediates the presence or intensity of other sensory domain symptoms, as well as by reports of atypical functional connectivity in the temporal pole region, a multisensory convergence zone associated with the processing of visual, olfactory and auditory stimuli [2]. Thus, involvement of cortical and subcortical brain areas and atypical functional connectivity of these areas may explain the contribution of the presence of multiple hypersensitivity symptoms to headache-related disability in our study.

In our study, psychological distress and number of migraine days per month were the relevant factors that contributed to headache-related disability. Chronic stress can be a major trigger for migraines and can amplify the intensity and frequency of headaches due to a hyperalgesic state related to central sensitization or through the activation of N-methyl-D-aspartate (NMDA) receptors or opioid receptors [17]. Relaxation following stress, prolonged fatigue, and extreme tension have been implicated in stress-triggered headaches [18]. Patients with migraine are 1.4 times more likely to develop stressrelated headaches than those with tension-type headaches [19]. Interestingly, the association between stressful events and headache was strongest in headache sufferers with low self-efficacy, and this association weakened as self-efficacy increased [20]. Preventive headache medication was significantly associated with MIDAS scores in the univariate analysis, but the significant difference disappeared in the multivariable analysis. The relationship between the use or non-use of preventive headache treatment and sensory hypersensitivity symptoms was not significant. Additionally, it is not clear from this study whether preventive headache treatment could mediate the reduction of the burden of migrainerelated disability by improving hypersensitivities.

Our study has several limitations. First, the study design was cross-sectional, and no healthy controls were included. Second, sensory hypersensitivity symptoms were self-reported by the patients, and the presence or absence of sensory symptoms was not assessed using a cutoff on the frequency or severity scale. We also did not assess the subjective severity and frequency of each sensory hypersensitivity symptom, or its degree of consistency or variability among episodes. Thus, it is not possible to explore the correlation between the intensity of hypersensitivities and the degree of migraine-related disability using only the data from this study. Finally, the study setting of an outpatient headache clinic at a university hospital, to which relatively severe cases are referred, may have influenced the results of the study.

\section{Conclusion}

Our study showed that sensory hypersensitivities commonly occur and overlap in patients with migraine and that multiple sensory hypersensitivity symptoms have significant impacts on headache-related disability. Further studies should collect objective measures of the frequency, severity, and overlap of sensory hypersensitivity symptoms and use headache diaries to track their association with headache attacks. Additionally, the efficacy of preventive treatment against sensory hypersensitivity symptoms needs to be evaluated by prospective studies. A better understanding of the relationship among the presence of multiple sensory hypersensitivity symptoms, the pathophysiology of migraine, and the degree of disease-related disability may enhance treatment opportunities.

\section{Abbreviations}

MIDAS: Migraine Disability Assessment; K6: Kessler Psychological Distress Scale

\section{Supplementary Information}

The online version contains supplementary material available at https://doi. org/10.1186/s10194-021-01294-8.

Additional file 1 .

\section{Acknowledgments}

The authors would like to thank Ms. Sanae Tani, Department of Neurology, Dokkyo Medical University, for help with this study. We also thank all of the participants who agreed to be involved in the study.

\section{Authors' contributions}

$\mathrm{KS}$ and $\mathrm{KH}$ conceived and designed the study. KS, SS, TS, MO and $\mathrm{KH}$ recruited the participants. KS drafted the paper. KS and YH performed the data analysis. SS, TS, MO, YH, MT and $\mathrm{KH}$ contributed to the interpretation and critically reviewed the manuscript. All of the authors read and approved the final version of the manuscript.

\section{Funding}

None.

\section{Availability of data and materials}

The data sets from this study are available from the corresponding author upon reasonable request.

\section{Declarations}

Ethics approval and consent to participate

The study was approved by the institutional review boards of the Dokkyo Medical University Hospital, and written informed consent was obtained from all patients who participated in the study.

\section{Consent for publication}

Not applicable.

\section{Competing interests}

None declared.

\section{Author details}

'Department of Neurology, Dokkyo Medical University, 880 Kitakobayashi, Mibu, Shimotsuga, Tochigi 321-0293, Japan. ${ }^{2}$ Integrated Research Faculty for Advanced Medical Science, Dokkyo Medical University School of Medicine, Tochigi, Japan. ${ }^{3}$ Medical Safety Management Center, Dokkyo Medical University Hospital, Tochigi, Japan. 
Received: 14 June 2021 Accepted: 12 July 2021

Published online: 19 July 2021

\section{References}

1. Ashina M, Katsarava Z, Do TP, Buse DC, Pozo-Rosich P, Ozge A, Krymchantowski AV, Lebedeva ER, Ravishankar K, Yu S, Sacco S, Ashina S, Younis S, Steiner TJ, Lipton RB (2021) Migraine: epidemiology and systems of care. Lancet 397(10283):1485-1495. https:/doi.org/10.1016/S0140-6736(20)32160-7

2. Schwedt TJ (2013) Multisensory integration in migraine. Curr Opin Neurol 26(3):248-253. https://doi.org/10.1097/WCO.0b013e328360edb1

3. Demarquay G, Royet JP, Giraud P, Chazot G, Valade D, Ryvlin P (2006) Rating of olfactory judgements in migraine patients. Cephalalgia 26(9):1123-1130. https://doi.org/10.1111/j.1468-2982.2006.01174.x

4. Ashkenazi A, Yang I, Mushtaq A, Oshinsky ML (2010) Is phonophobia associated with cutaneous allodynia in migraine? J Neurol Neurosurg Psychiatry 81(11):1256-1260. https://doi.org/10.1136/jnnp.2009.198481

5. Kelman L, Tanis D (2006) The relationship between migraine pain and other associated symptoms. Cephalalgia 26(5):548-553. https://doi.org/10.1111/j.14 68-2982.2006.01075.x

6. Headache Classification Committee of the International Headache Society (IHS) The International Classification of Headache Disorders, 3rd edition (2018). Cephalalgia 38(1):1-211. https://doi.org/10.1177/0333102417738202

7. Stewart WF, Lipton RB, Whyte J, Dowson A, Kolodner K, Liberman JN, Sawyer J (1999) An international study to assess reliability of the migraine disability assessment (MDAS) score. Neurology 53(5):988-994. https:/doi.org/10.1212/wnl.53.5.988

8. Furukawa TA, Kawakami N, Saitoh M, Ono Y, Nakane Y, Nakamura Y, Tachimori H, Iwata N, Uda H, Nakane H, Watanabe M, Naganuma Y, Hata Y, Kobayashi M, Miyake Y, Takeshima T, Kikkawa T (2008) The performance of the Japanese version of the K6 and K10 in the world mental health survey Japan. Int J Methods Psychiatr Res 17(3):152-158. https://doi.org/10.1002/mpr.257

9. Leveque Y, Masson R, Fornoni L, Moulin A, Bidet-Caulet A, Caclin A, Demarquay G (2020) Self-perceived attention difficulties are associated with sensory hypersensitivity in migraine. Rev Neurol (Paris) 176(10):829-838. https://doi.org/10.1016/j.neurol.2020.01.360

10. Wang X, Yin Z, Lian Y, Xu Y, Li Y, Liu J, Gu Q, Yan F, Ge Z, Lian Y, Hu D, Chen S, Wang R, Chen X, Liu J, Zhang M, Ran Y, Zhou P, Ma J, Lv X, Dong Z, Yu S (2021) Premonitory symptoms in migraine from China: a multi-clinic study of 4821 patients. Cephalalgia:333102421997850. https:/doi.org/10.1177/0333102421997850

11. Karsan N, Goadsby PJ (2018) Biological insights from the premonitory symptoms of migraine. Nat Rev Neurol 14(12):699-710. https://doi.org/10.1 038/s41582-018-0098-4

12. Schulte LH, Jurgens TP, May A (2015) Photo-, osmo- and phonophobia in the premonitory phase of migraine: mistaking symptoms for triggers? J Headache Pain 16(1):14. https://doi.org/10.1186/s10194-015-0495-7

13. Schwedt TJ, Chiang CC, Chong CD, Dodick DW (2015) Functional MRI of migraine. Lancet Neurol 14(1):81-91. https://doi.org/10.1016/S1474-4422(14)70193-0

14. Stankewitz A, May A (2011) Increased limbic and brainstem activity during migraine attacks following olfactory stimulation. Neurology 77(5):476-482. https://doi.org/10.1212/WNL.0b013e318227e4a8

15. Vincent M, Pedra E, Mourao-Miranda J, Bramati IE, Henrique AR, Moll J (2003) Enhanced interictal responsiveness of the migraineous visual cortex to incongruent bar stimulation: a functional MRI visual activation study. Cephalalgia 23(9):860-868. https://doi.org/10.1046/j.1468-2982.2003.00609.x

16. Demarquay G, Mauguiere $F$ (2016) Central nervous system underpinnings of sensory hypersensitivity in migraine: insights from neuroimaging and electrophysiological studies. Headache 56(9):1418-1438. https:/doi.org/10.1111/head.12651

17. Sauro KM, Becker WJ (2009) The stress and migraine interaction. Headache 49(9):1378-1386. https://doi.org/10.1111/j.1526-4610.2009.01486.x

18. Spierings EL, Sorbi M, Maassen GH, Honkoop PC (1997) Psychophysical precedents of migraine in relation to the time of onset of the headache: the migraine time line. Headache 37(4):217-220. https://doi.org/10.1046/.1526-4610.1997.3704217.x

19. Zivadinov R, Willheim K, Sepic-Grahovac D, Jurjevic A, Bucuk M, BrnabicRazmilic O, Relja G, Zorzon M (2003) Migraine and tension-type headache in Croatia: a population-based survey of precipitating factors. Cephalalgia 23(5):336-343. https://doi.org/10.1046/j.1468-2982.2003.00544.x

20. Marlowe N (1998) Self-efficacy moderates the impact of stressful events on headache Headache 38(9):662-667. https:/doi.org/10.1046/j.1526-4610.1998.3809662x

\section{Publisher's Note}

Springer Nature remains neutral with regard to jurisdictional claims in published maps and institutional affiliations.

Ready to submit your research? Choose BMC and benefit from:

- fast, convenient online submission

- thorough peer review by experienced researchers in your field

- rapid publication on acceptance

- support for research data, including large and complex data types

- gold Open Access which fosters wider collaboration and increased citations

- maximum visibility for your research: over $100 \mathrm{M}$ website views per year

At $\mathrm{BMC}$, research is always in progress.

Learn more biomedcentral.com/submissions 